\title{
Surface Morphology of Basalt Columns at Svartifoss, VatnajökulsPjóðgarður, Southern Iceland
}

\author{
Lawrence H. Tanner \\ Department of Environmental Science Systems, Le Moyne College, Syracuse, NY 13214, USA \\ Correspondence should be addressed to Lawrence H. Tanner; tannerlh@lemoyne.edu
}

Received 3 August 2013; Revised 2 October 2013; Accepted 2 October 2013

Academic Editor: Karoly Nemeth

Copyright (C) 2013 Lawrence H. Tanner. This is an open access article distributed under the Creative Commons Attribution License, which permits unrestricted use, distribution, and reproduction in any medium, provided the original work is properly cited.

\begin{abstract}
A spectacular example of columnar-jointed basalt occurs at Svartifoss in the Vatnajökull National Park of southern Iceland. The columns are notable for a variety of features on the vertical joint surfaces and the horizontal parting surfaces. The jointed surfaces of the columns display horizontal striations at a spacing of centimeters to decimeters. The individual striations exhibit crescentic hackles with a plumose pattern, the orientation of which varies between adjacent striations. Also present are gently dipping, millimeter-scale laminations not previously described. Horizontal parting surfaces of the columns display a circular ring that inscribes most of the diameter column. The ring features alternately positive or negative relief against the perimeter of the column and exhibits a radiating pattern of hackles originating at the center of the ring. Petrographic examination reveals that the basalt contains an interlocking network of plagioclase laths preferentially aligned perpendicular to the column axes. The circular features have been described previously and attributed to late-stage melt migration driven by a load-induced pressure gradient. The striations were formed from stepwise, downward propagation of the polygonal fracture system, and the plumose structures were formed from tensile stresses during fracture propagation. The small-scale laminations may result from preferential grain alignment of plagioclase laths.
\end{abstract}

\section{Introduction}

Columnar-jointed basalts, which have been found on all continents, are among the most widely recognizable features of basalt volcanism. Indeed, often they are one of the first igneous features to be correctly identified by students in introductory geology classes. The textbooks used in such classes ascribe the formation of columnar jointing to the volume change (contraction) of flows or shallow intrusions as they cool from the top down (e.g., see [1]). These simplistic explanations are more or less correct at a very basic level, but they do nothing to explain why cooling and the consequent volume changes cause the formation of a regular fracture pattern. In great part, this lack of specificity is derived from the lack of widespread agreement among igneous petrologists themselves on a precise mechanism of formation since their interpretation by Mallet [2]. Subsequent contributions include those of James [3], Tomkeieff [4], Spry [5], Jaeger [6], Peck and Minakami [7], Reiter et al. [8], and Aydin and DeGraff [9]. Goehring et al. [10] used corn-starch analog experiments to derive a scaling law that applies to contraction due to both differential drying and cooling. Gilman [11], however, rejected thermal contraction as a sufficient explanation, citing the inability of fracture patterns of great regularity to be formed in homogeneous brittle materials in homogeneous stress fields, and presents as an alternative mechanism constitutional supercooling, which generates instabilities at the solid-melt interface, resulting in inhomogeneous patterned compositions. More recently, Mattsson et al. [12] proposed that progressive cooling and crystallization, in combination with vertical loading, create a pressure gradient that drives melt migration parallel to the column axis, causing viscous fingering that is the ultimate control on the uniformity of column formation.

Beyond the colonnades themselves, numerous authors have described and remarked on the potential origins of the various types of ornamentation that are apparent on the faces of the columns or on the parting surfaces, such as the horizontal grooves or striations that are common on the vertical faces of the columns [10,13-16], the plumose patterns 


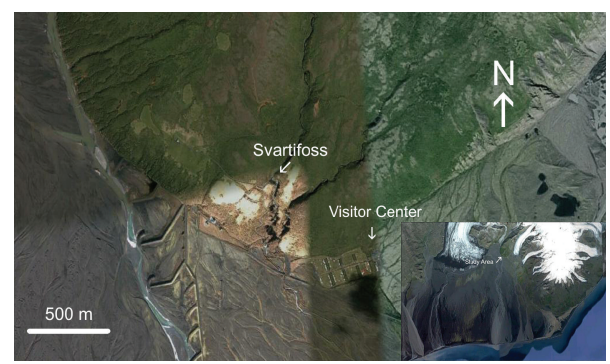

Figure 1: Location of the field area near the southern coast of Iceland. The Visitor Center is the park headquarters building at Skaftafell. The glaciers in the inset are outlet glaciers of the Vatnajökull ice sheet. Figure is adapted from Google Earth imagery.

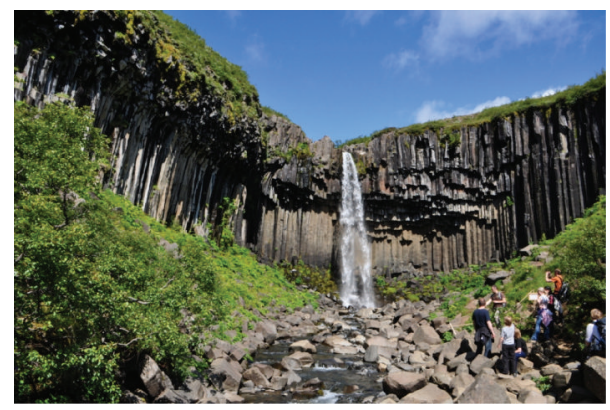

Figure 2: View of Svartifoss from the south, along the banks of Bæjargil. The bending of the top of the colonnade can be seen to the upper left. Multiple tiers of hanging columns are visible in the upper part of the colonnade.

of hackles that often occur within the striations $[9,13,17]$, and inscribed circular features within the columns $[12,18,19]$. This study documents the occurrence of all of these morphological features on the basalt columns at Svartifoss and describes an additional feature not previously described. The mechanisms of formation of these features are discussed briefly.

\section{Location}

The former Skaftafell National Park of southern Iceland, the most visited of Iceland's national parks, is now encompassed within the much larger Vatnajökulspjóðgarður (Vatnajökull National Park), which was created to include most of the Vatnajökull ice sheet, in addition to other geological features requiring preservation, such as the Laki Craters and the Askja Caldera. Svartifoss or Black Falls (N $66^{\circ} 01^{\prime} 40.1^{\prime \prime}$, W $16^{\circ} 58^{\prime} 33.2^{\prime \prime}$ ) sits $140 \mathrm{~m}$ above the coastal plain and is accessed by a $1.5 \mathrm{~km}$ trail from a parking area at Skaftafell (Figure 1). The basalt exposure at Svartifoss (Figure 2) features a single flow colonnade without entablature approximately 15 to $20 \mathrm{~m}$ high and approximately $30 \mathrm{~m}$ wide [20]. The south-facing cliff forms a V-shaped notch by headward erosion from the stream Bæjargil. On the west side of the notch, the columns in the upper part of the colonnade exhibit bending to the southeast. Undercutting of the cliff has left as many as eight tiers of columns in the colonnade hanging without basal support and provided ready access to the numerous detached columns on the stream banks that are studies here.

\section{Materials and Methods}

The material examined for this study consisted entirely of detached column blocks situated along the sides of the stream. Many of these blocks preserve the entire column diameter, while others are fragments of columns broken longitudinally. Samples collected in the field were analyzed by preparing standard petrographic thin sections $(30 \mu \mathrm{m}$ thickness) cut in three mutually perpendicular axes, $a, b$, and $c$, with the $c$-axis parallel to the direction of elongation of the column. Samples were prepared for scanning electron microscopy by gold coating. The specimens were examined using a JEOL JSM-6510LV microscope operating at $20 \mathrm{kV}$ and imagined with both secondary and backscattered electron detectors.

\section{Observations}

4.1. Macromorphological Features. The basalt blocks that preserve the entire column thickness have a diameter of $0.6 \mathrm{~m}$ to $1.2 \mathrm{~m}$ (mean $=0.97 \mathrm{~m} ; n=37$ ). Except where broken longitudinally, the columns display a hexagonal shape in cross-section. Additionally, the following morphological features occur on the surfaces of the columns.

4.1.1. Horizontal Banding. The sides of the columns are corrugated by horizontal bands that are present around the entire perimeter of the columnar fragment (Figure 3(a)) although individual bands are commonly offset vertically from one face to the next; that is, the boundaries of the bands are not continuous across adjoining faces. The vertical height was measured for c. 200 bands, which range from $5 \mathrm{~cm}$ to $20 \mathrm{~cm}$ and average $10.2 \mathrm{~cm}$ in height. On any individual face, the height of the bands is relatively uniform, but variations do occur where the height of adjacent bands may vary by as much as a factor of three (Figure 3(b)). On some faces, the surface of the bands lacks relief; that is, the surface is flat (Figure 3(c)). More commonly, however, the bands have either convex or concave relief (Figure $3(\mathrm{~d})$ ). The relief is consistent on one side of the column; that is, on a single column face, all of the bands will be either concave or convex. However, the relief commonly differs between adjoining faces; that is, the bands may be concave on one face of the column and convex on the adjoining face.

4.1.2. Crescent-Shaped Hackles. The surfaces of most of the horizontal bands described above bear a hackly fracture pattern in which the hackles are oriented vertically, extending from the top to the base of an individual band (Figure 4(a)). The hackles commonly curve toward the base of the band in which they occur, producing a crescent-like shape. Additionally, the hackles display increasing relief toward the base of the band in which they occur and may be almost indiscernible near the top of the band. The orientation of the curvature most often is consistent within a single horizontal 


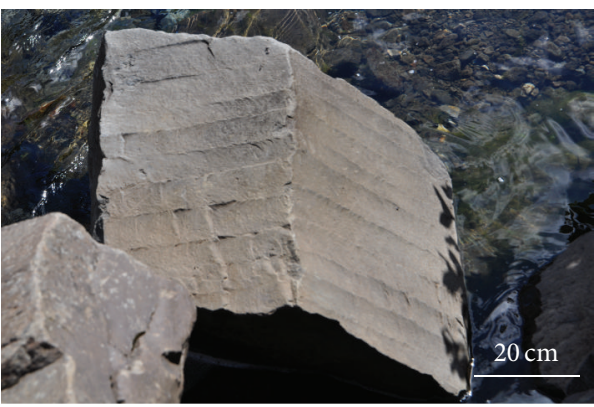

(a)

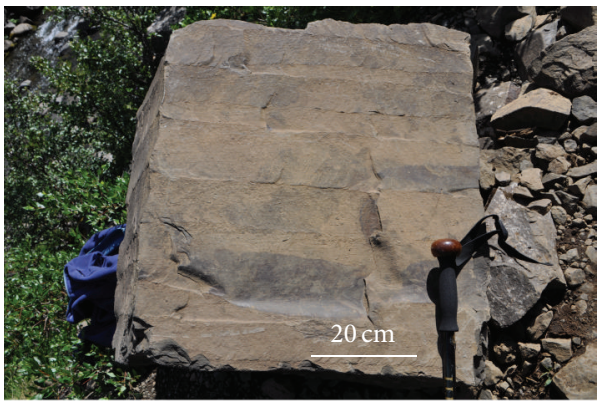

(c)

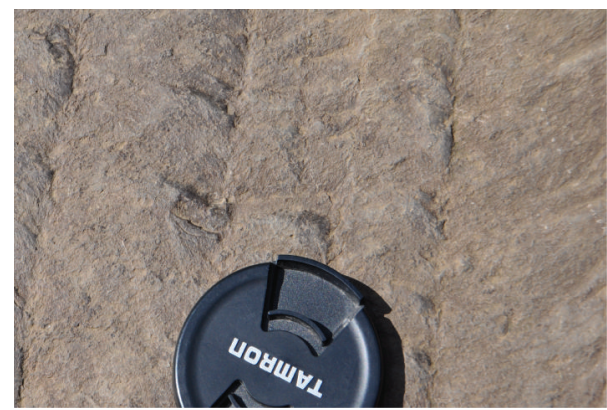

(b)

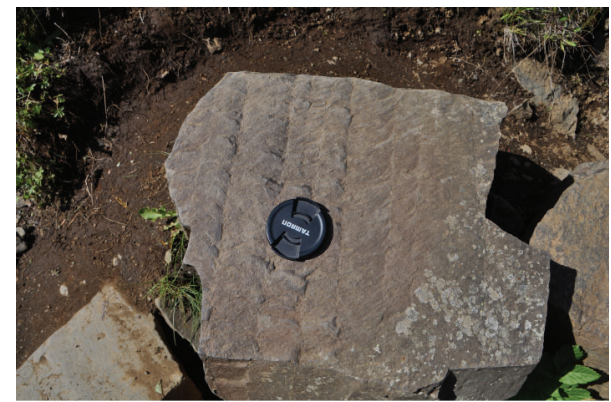

(d)

FIGURE 3: Aspects of the horizontal striations on the columnar joint faces. (a) Striations are generally visible on multiple sides of column fragments. Note that striations from one side are not continuous to other sides. (b) Striations are variable in width, ranging from $30 \mathrm{~mm}$ to $60 \mathrm{~mm}$ in this view (lens cap is $72 \mathrm{~mm}$ ). (c) Joint surface on which the striations are neither concave nor convex. (d) Striations on this surface have convex relief (as opposed to the concave relief in (a)).

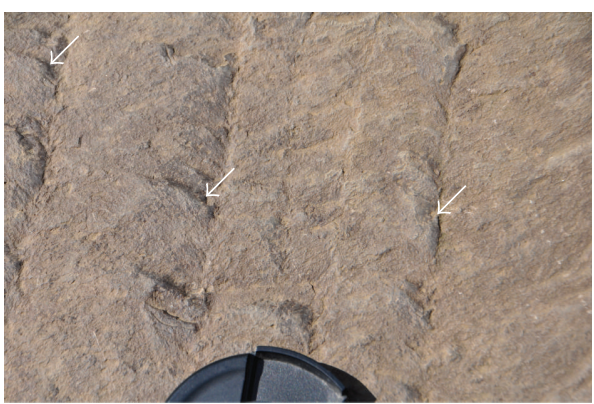

(a)

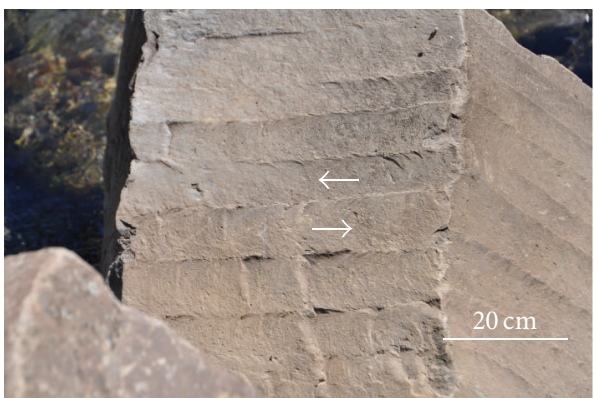

(c)

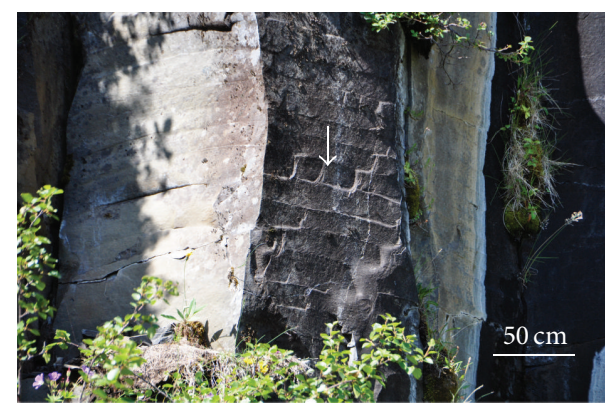

(b)

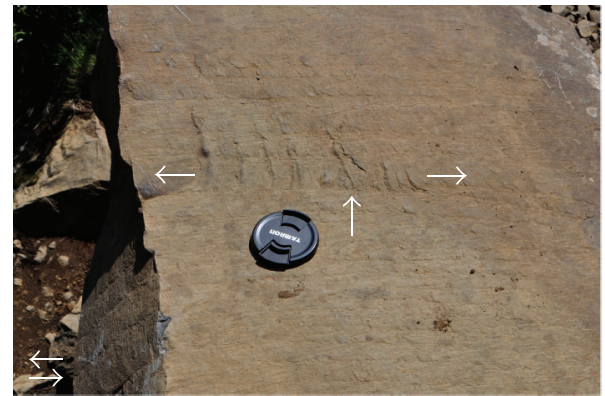

(d)

Figure 4: Aspects of hackled surfaces within the horizontal striations. (a) Crescent-shaped hackling is a common surface feature on the horizontal striations. Arrows indicate base of striation (lens cap diameter is $72 \mathrm{~mm}$ ). (b) The relief of the hackles is more pronounced near the lower margin of the striation in which they occur (arrows). (c) The orientation of the curvature of the hackles commonly reverses between adjacent striations (arrows indicate direction in which the curvature opens). (d) In rare instances, the orientation of the hackle curvature reverses within a striation. Vertical arrow indicates the point of reversal; horizontal arrows indicate orientation of curvature. 


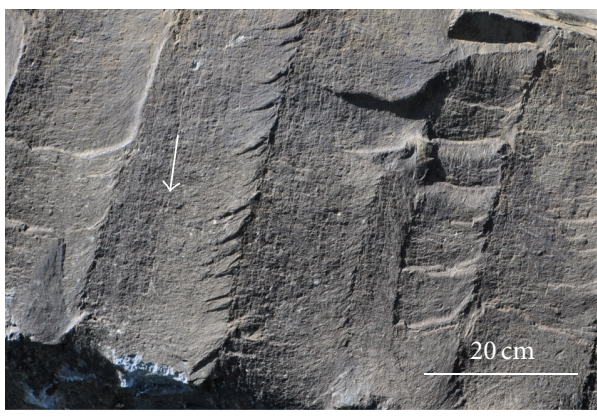

(a)

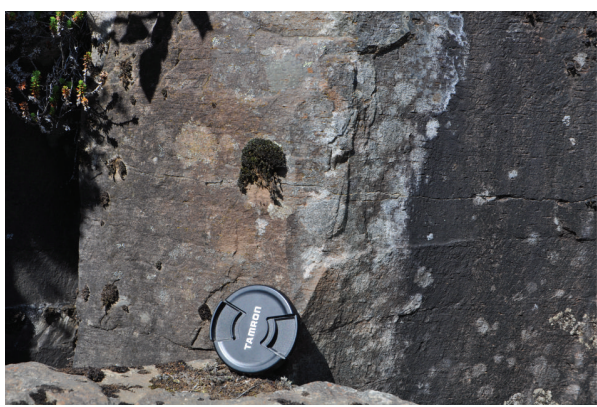

(c)

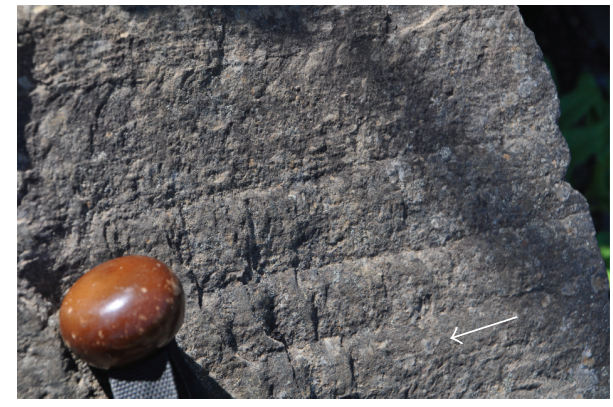

(b)

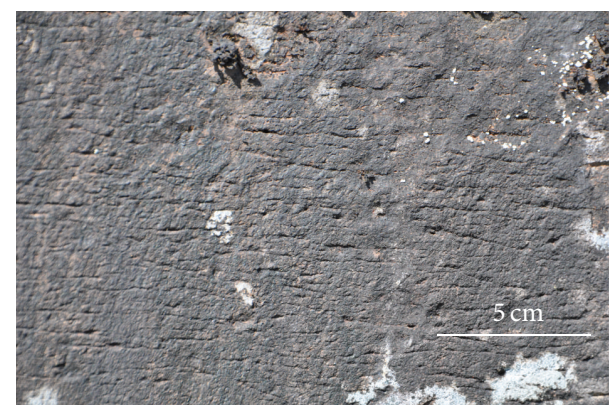

(d)

FIGURE 5: Types of laminations that occur on the joint surfaces. (a) Fine, nearly parallel laminae that dip gently (arrow parallel to dip) to cross-cut hackles. (b) Fine laminations occur also on concave striation surfaces (arrow parallel to laminations). Width of wooden knob on staff is $5 \mathrm{~cm}$. (c) In situ column on which no striations are evident on joint surfaces, but irregular wavy indentations are visible (lens cap is $72 \mathrm{~mm}$ ). (d) Detail of (c) illustrating discontinuous nature of the laminar indentations.

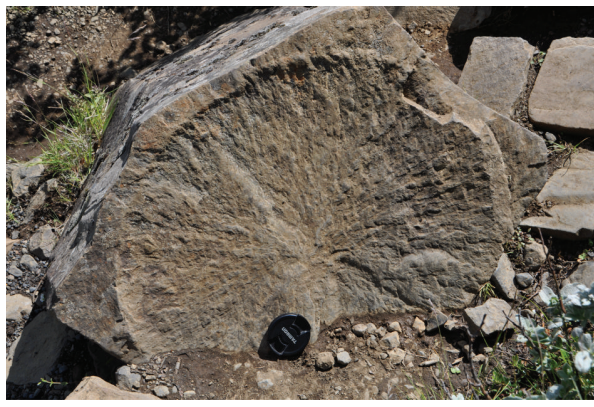

(a)

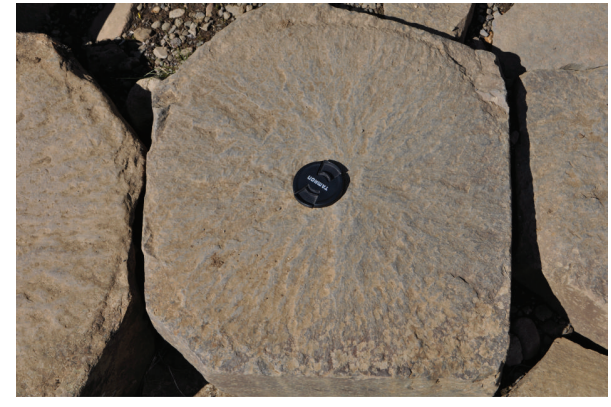

(b)

FIGURE 6: Inscribed circles on horizontal parting surfaces, with (a) negative and (b) positive relief. Radiating pattern of hackles within the circle is visible in both views.

band although this orientation commonly reverses from one band to the next (Figures 4(b) and 4(c)). In some instances, however, the orientation of the hackles reverses midway across the band (Figure $4(\mathrm{~d})$ ).

4.1.3. Fine Laminations. A pattern of fine laminations is visible within many of the horizontal bands (Figures 5(a) and $5(\mathrm{~b})$ ). The laminations are roughly, but not precisely, parallel and evenly spaced at approximately $5 \mathrm{~mm}$ and dip at angles varying from $10^{\circ}$ to $25^{\circ}$. The laminations are confined within individual horizontal bands; that is, they initiate at the top of the band, are truncated at the base, but cross-cut the crescentic hackles described above. On some column surfaces, neither the horizontal bands nor the crescentic hackles are well developed. These surfaces sometimes exhibit laminations that are irregular and discontinuous. On weathered surfaces, the laminations are characterized by indentations approximately $1 \mathrm{~mm}$ wide, that are slightly wavy (Figures 5(c) and 5(d)).

4.1.4. Features on Parting Surfaces. On most column fragments, the horizontal parting surface exposes an inscribed circle with either positive or negative relief of several millimeters with respect to the surrounding rim (Figure 6(a)). The circles occupy almost all of the parting surfaces, aside from the surrounding rim. In many instances, the circles extend 


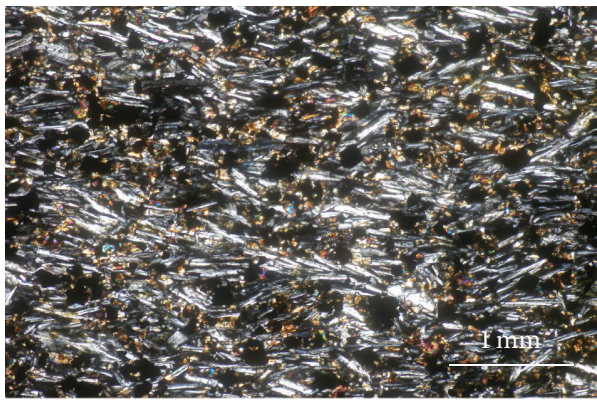

(a)

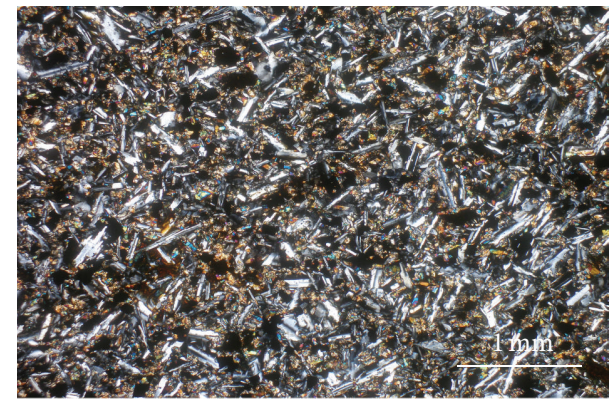

(b)

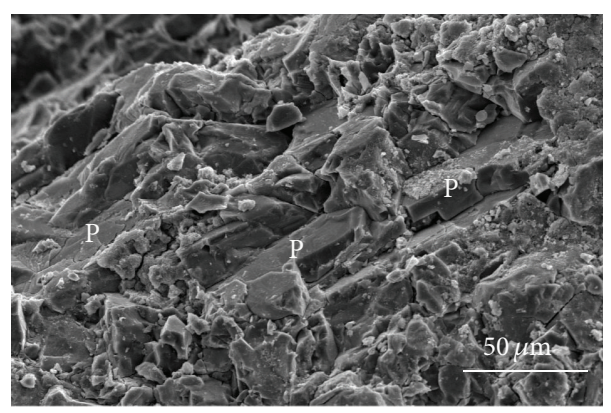

(c)

Figure 7: Microscopic features of the basalts. (a) Planar arrangement of linked plagioclase laths is evident in this view oriented parallel to vertical axis of basalt column. Other minerals are clinopyroxene (bright) and titanomagnetite (opaque). (b) Horizontal view (perpendicular to $c$-axis) demonstrates abundant linkage on plagioclase laths but not with preferred orientation as in (a). (c) Scanning electron micrograph of sample surface oriented approximately horizontally demonstrates preferential orientation of plagioclase (P) in $a-b$ plane.

to the outer edge of the column (Figure 6(b)), although just as commonly a rim of several centimeters separates the circle from the column face. A somewhat wider rim occurs on the column corners. Within the inscribed circles, the basalt surface is covered by a pattern of radiating hackles that originate at the center of the circle and end at abruptly the margin of the circle. The hackles form a pattern of ridges and indentations with $1 \mathrm{~mm}$ to $2 \mathrm{~mm}$ of relief radiating from the center of the inscribed circle. Although there is a general trend for the hackles to thicken away from the center, individual hackles are instead very irregularly shaped and exhibit abrupt thickening and thinning.

4.2. Micromorphology. Several samples collected in the field were analyzed by cutting petrographic thin sections in three mutually perpendicular axes, $a, b$, and $c$, with the $c$-axis parallel to the direction of elongation of the column. The rock comprises plagioclase, clinopyroxene, and titanomagnetite with a seriate intergranular texture. A high degree of linkage of the plagioclase laths is apparent in all directions, but thin sections cut parallel to the $c$-axis demonstrate preferential orientation of the plagioclase laths, which form chains up to $2 \mathrm{~mm}$ in length, parallel to the $a-b$ plane (Figures 7 (a) and 7(b)). Several specimens were examined by scanning electron microscopy and imaging reveals the same preferential alignment of plagioclase laths seen in thin section (Figure $7(\mathrm{c})$ ).

\section{Discussion}

5.1. Horizontal Striations. The horizontal corrugation or striations on the vertical column surfaces were described by Spry [5] and explained by Budkewitsch and Robin [14] as the result of the stepwise downward advance of the polygonal fracture pattern. Further, these authors stated that if adjacent columns are unequal in size, the asymmetry of the isotherms between the two columns will drive the crack toward the larger column. Hence, the smaller column will form corrugations with convex surfaces, and the facing surface of the larger adjacent column will form concave surfaces. This prediction cannot be confirmed by examination of the disconnected column fragments studied here, but it is notable that the largest columns at Svartifoss, which remain in situ in the cliff face, display no relief on the striation surfaces (Figure 4(b)). Perhaps in the interior of the flow, isotherms between adjacent flows are equal, and consequently the fracture propagates downward evenly between columns.

According to Grossenbacher and McDuffle [15], the vertical height of the striations varies inversely with the thermal gradient developed during cooling; a steeper gradient results in narrower striations. Because column diameter is related (inversely) to cooling rate, the ratio of striation width to column diameter is also constant where the ratio of the thermal gradient to cooling rate remains constant. Goehring et al. [10], however, described striation thickness as controlled instead by the velocity of cooling, or more precisely, as 
correlating inversely with the velocity at which the cooling front advances. Goehring and Morris [16] also specified that the width of striations generally correlates with the width of the columns, although this is not a rule; they observed that the striation width can vary by as much as a factor of three on a single column. These conclusions are consistent with the observations at Svartifoss. The striations on the columns do not display exact uniformity of width; within any grouping, many of the striations may be of similar width, but some will be distinctly thicker or thinner than the mean, as in Figure 3(b).

Ryan and Sammis [13] and Grossenbacher and McDuffie [15] described individual striations as consisting of both a smooth surface and a rough surface. The former authors interpreted these as formed by alternating elastic failure (smooth) and nonelastic failure (rough) during fracture propagation. The latter authors further specified that the smoother bands are the earlier, faster formed portion of the fracture increment, followed by the slower, rougher band. Hence, the vertical smooth/rough sequence is an indicator of the direction of fracture propagation, that is, top down versus bottom up [13]. Close examination of the work by Ryan and Sammis [13] and comparison with the striations on the Svartifoss columns suggest that the smooth versus rough textures described by these earlier authors are a function of the relief of the hackles within the striations, described below. This apparent smooth/rough pattern is most apparent in striations on the Svartifoss columns that have a flat surface, as in Figure 3(c), but is less apparent to completely lacking in those with a convex surface (Figure 3(b)). Where it is apparent, however, the "rough" surface occurs near the base of the striation, suggesting fracture propagation from the top, progressing downward, in contrast to those measured in Hawaii by Ryan and Sammis [13].

5.2. Crescentic Hackles. The crescentic hackles that occupy the vertical area within striations were first described by Ryan and Sammis [13], who termed them fracture lances and interpreted them as relicts of rotational shear during thermal fracturing. Aydin and DeGraff [9] and DeGraff and Aydin [17] described the crescentic hackles as plumose structures formed during fracturing, with the hackles oriented in a direction radiating away from the fracture origin in the direction of fracture propagation. However, the point of fracture origin is simply a point of weakness that provides a nucleation site. Hence, there is no consistency to the direction of propagation; the orientation of the plumose structures commonly reverses from one striation to the next, as noted by Aydin and DeGraff [9] and as observed at Svartifoss. Where the nucleation point occurs in the middle of the column face, rather than at the corner junction of three columns (a triple junction of Aydin and DeGraff [9]), the plumes will radiate away from the point in both directions. Most of the plumose structures observed at Svartifoss maintain a consistent orientation across the column face, indicating nucleation at the corners, although a very few instances exhibit a change in orientation mid-face.
5.3. Inscribed Circles. Guy [19], in commenting on the mechanism of constitutional supercooling of Gilman [11], described circular features inscribed within column polygons and suggested that they are a logical consequence of the compositional heterogeneity predicted by compositional supercooling. Guy [19] further noted the occurrence of a radiating pattern of hackly features originating from the center of the inscribed circles but was unable to offer a viable mechanism for their formation. Mattsson et al. [12] also noted that the inscribed semicircles are among the most common features on the parting surfaces of columnar basalts and offered the most comprehensive explanation of their formation to date. These authors noted that thermodynamics predicts a volume change of $15 \%$ during cooling. Initially, heat is lost predominantly to the upper surface, but as fractures propagate downward, heat loss to the sides of the columns becomes more important. They proposed that, synchronous with the volume decrease during crystallization, vertical loading creates a pressure gradient that drives vertical melt migration from the base of the melt body to the interior of the columns, thereby maintaining their consistent diameter; this interpretation is supported by both petrographic and measurements of the anisotropy of magnetic susceptibility.

Notably, Bermúdez and Delpino [18] reported on a pattern of concentric and radiating joints within a columnarjointed, gabbroic sill. They attribute the concentric jointing to convective processes within the columns, an interpretation that seems to have foreshadowed the work of Mattsson et al. [12]. They attributed the radiating joint patterns to thermal stresses during cooling. However, the joint patterns described by Bermúdez and Delpino [18] differ significantly from the inscribed circles and radiating hackles described here; their concentric joints have the "onion-skin" morphology often associated with spheroidal weathering, and the radiating joints they described are not linear features and do not originate from the center of the inscribed circle as they do at Svartifoss (Figure 6(a)).

Guy [19] also noted the radiating hackle pattern within the inscribed circles and rejected the hypothesis that they originate from thermal stress but offers no alternative hypothesis. The key point of his argument is the assumption that, because the hackles converge at the center of the circle, they must have originated from there and propagated outward. Here, I offer the alternate hypothesis that the hackles represent instead a plumose pattern formed by tensile fracture of the column perpendicular to the column axis. The relief between the inscribed circle and the periphery represents differences in tensile strength between the early crystallized outer column and the later crystallized inner column.

Mattsson et al. [12] noted the presence of plagioclase lath networks in the columnar basalts at Hrepphólar (Iceland). These networks were first noted by Philpotts et al. [21] and Philpotts and Dickson [22], who found, through experimentation, that three-dimensional networks formed near the solidus interface early in the crystallization process, perhaps as early as $25 \%$ solid ( $75 \%$ melt). Chains of plagioclase laths are formed in order to lower the surface energy of the individual crystals. As noted by Mattson et al. [12], the plagioclase lath chains resist deformation but remain 
permeable. At $50 \%$ crystallization, the density of the remaining melt decreases with only minimal viscosity increase. Moreover, the melt mobility increases with titanomagnetite saturation. A weak horizontal alignment of the network can result from compaction, as observed in the Holyoke Basalt (Philpotts et al.) [21]. The subplanar alignment of these chains in the $a-b$ plane (Figures 7(a) and 7(c)) may explain one of the more subtle macromorphological features, the millimeter-scale laminations that are observed within the striations (Figures 5(a) and 5(b)). The presence of these chains preferentially near the exterior of the columns, where heat loss is greatest, likely explains the differential strength of the column perimeter as compared to the inscribed circle.

\section{Conclusions}

The observations of the basalts at Svartifoss presented here, for example, striated column surfaces, inscribed circular forms, and oriented plagioclase lath networks, all conform to the observations presented previously of columnar-jointed basalts at other locations. Nevertheless, some of the features described here, such as the gently inclined, fine laminations within the striations, have not been described previously. Additionally, some of these features, such as the radiating hackle pattern within the inscribed circles, have not been explained satisfactorily in previous studies.

The observations from Svartifoss are consistent with the melt-migration model of basalt column formation of Mattsson et al. [12], which itself relies on the formation of plagioclase lath chains. The plagioclase laths form a network that is aligned preferentially in the $a-b$ plane due to the loadinduced pressure gradient at the margins of the column. In addition to playing a role in melt migration, which is responsible for the circular centers of the columns, the plagioclase laths appear to form networks with a preferentially horizontal orientation that may be responsible for the fine laminations on the column vertical joint surfaces. The strength provided by lath networks at the margins of the columns also may explain the difference in parting strength that creates the inscribed circles and surrounding periphery on the horizontal parting surfaces of the columns.

\section{Acknowledgments}

Development of the ideas presented in this paper benefitted from discussions with B. Martin. An anonymous reviewer improved this paper through careful work and thoughtful comments.

\section{References}

[1] S. Marshak, Earth: Portrait of a Panet, W. W. Norton \& Company, New York, NY, USA, 2011.

[2] R. Mallet, "On the origin or production of the prismatic (or columnar) structure of basalt," Philosophical Magazine, vol. 50, no. 4, pp. 122-135, 1875.

[3] A. V. G. James, "Factors producing columnar structure in lavas and its occurrence near Melbourne, Australia," Journal of Geology, vol. 28, pp. 458-469, 1920.
[4] S. I. Tomkeieff, "The basalt lavas of the Giant's Causeway district of Northern Ireland," Bulletin Volcanologique, vol. 6, no. 1, pp. 89-143, 1940.

[5] A. Spry, "The origin of columnar jointing, particularly in basalt flows," Geological Society of Australia, vol. 8, no. 2, pp. 191-215, 1962.

[6] J. C. Jaeger, "Cooling and solidification of igneous rocks," in Basalts: the Poldervaart Treatise on Rocks of Basaltic Composition, H. H. Hess and A. Poldervaart, Eds., vol. 2, pp. 503-535, John Wiley \& Sons, New York, NY, USA, 1967.

[7] D. L. Peck and T. Minakami, "The formation of columnar joints in the upper part of Kilauean lava lakes, Hawaii," Geological Society of America Bulletin, vol. 79, pp. 1151-1166, 1968.

[8] M. Reiter, M. W. Barroll, J. Minier, and G. Clarkson, "Thermomechanical model for incremental fracturing in cooling lava flows," Tectonophysics, vol. 142, no. 2-4, pp. 241-260, 1987.

[9] A. Aydin and J. M. DeGraff, "Evolution of polygonal fracture patterns in lava flows," Science, vol. 239, no. 4839, pp. 471-476, 1988.

[10] L. Goehring, L. Mahadevan, and S. W. Morris, "Nonequilibrium scale selection mechanism for columnar jointing," Proceedings of the National Academy of Sciences of the United States of America, vol. 106, no. 2, pp. 387-392, 2009.

[11] J. J. Gilman, "Basalt columns: large scale constitutional supercooling?" Journal of Volcanology and Geothermal Research, vol. 184, no. 3-4, pp. 347-350, 2009.

[12] H. B. Mattsson, L. Caricchi, B. S. G. Almqvist et al., "Melt migration in basalt columns driven by crystallization-induced pressure gradients," Nature Communications, vol. 2, no. 1, article 299, 2011.

[13] M. P. Ryan and C. G. Sammis, "Cyclic fracture mechanisms in cooling basalt," Geological Society of America Bulletin, vol. 89, pp. 1295-1308, 1978.

[14] P. Budkewitsch and P.-Y. Robin, "Modelling the evolution of columnar joints," Journal of Volcanology and Geothermal Research, vol. 59, no. 3, pp. 219-239, 1994.

[15] K. A. Grossenbacher and S. M. McDuffie, "Conductive cooling of lava: columnar joint diameter and stria width as functions of cooling rate and thermal gradient," Journal of Volcanology and Geothermal Research, vol. 69, no. 1-2, pp. 95-103, 1995.

[16] L. Goehring and S. W. Morris, "Length scales in columnar jointing of the Columbia Basalt Group," in Proceedings of the American Geophysical Union, Fall Meeting, vol. 85, no. 47, EOS, 2004.

[17] J. M. DeGraff and A. Aydin, "Surface morphology of columnar joints and its significance to mechanics and direction of joint growth," Geological Society of America Bulletin, vol. 99, pp. 605617, 1987.

[18] A. Bermúdez and D. H. Delpino, "Concentric and radial joint systems within basic sills and their associated porosity enhancement, Neuquén Basin, Argentina," Geological Society Special Publication, no. 302, pp. 185-198, 2008.

[19] B. Guy, "Comments on "Basalt columns: large scale constitutional supercooling? by John Gilman (JVGR, 2009) and presentation of some new data [J. Volcanol. Geotherm. Res. 184 (2009), 347-350]," Journal of Volcanology and Geothermal Research, vol. 194, no. 1-3, pp. 69-73, 2010.

[20] G. Hetényi, B. Taisne, F. Garel, É. Médard, S. Bosshard, and H. B. Mattsson, "Scales of columnar jointing in igneous rocks: field measurements and controlling factors," Bulletin of Volcanology, vol. 74, no. 2, pp. 457-482, 2012. 
[21] A. R. Philpotts, J. Shi, and C. Brustman, "Role of plagioclase crystal chains in the differentiation of partly crystallized basaltic magma," Nature, vol. 395, no. 6700, pp. 343-346, 1998.

[22] A. R. Philpotts and L. D. Dickson, "The formation of plagioclase chains during convective transfer in basaltic magma," Nature, vol. 406, no. 6791, pp. 59-61, 2000. 

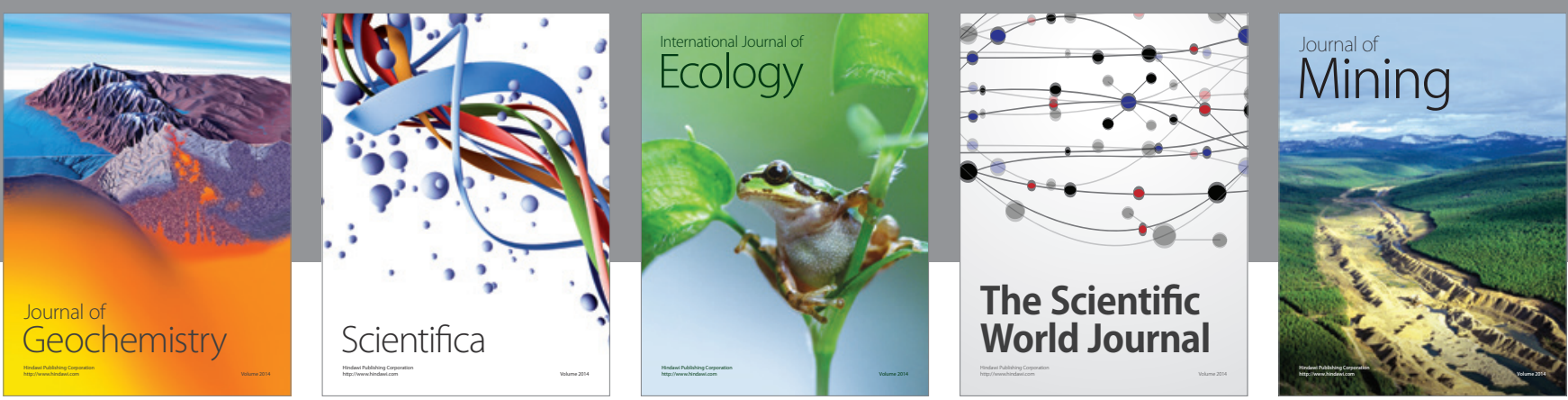

The Scientific World Journal
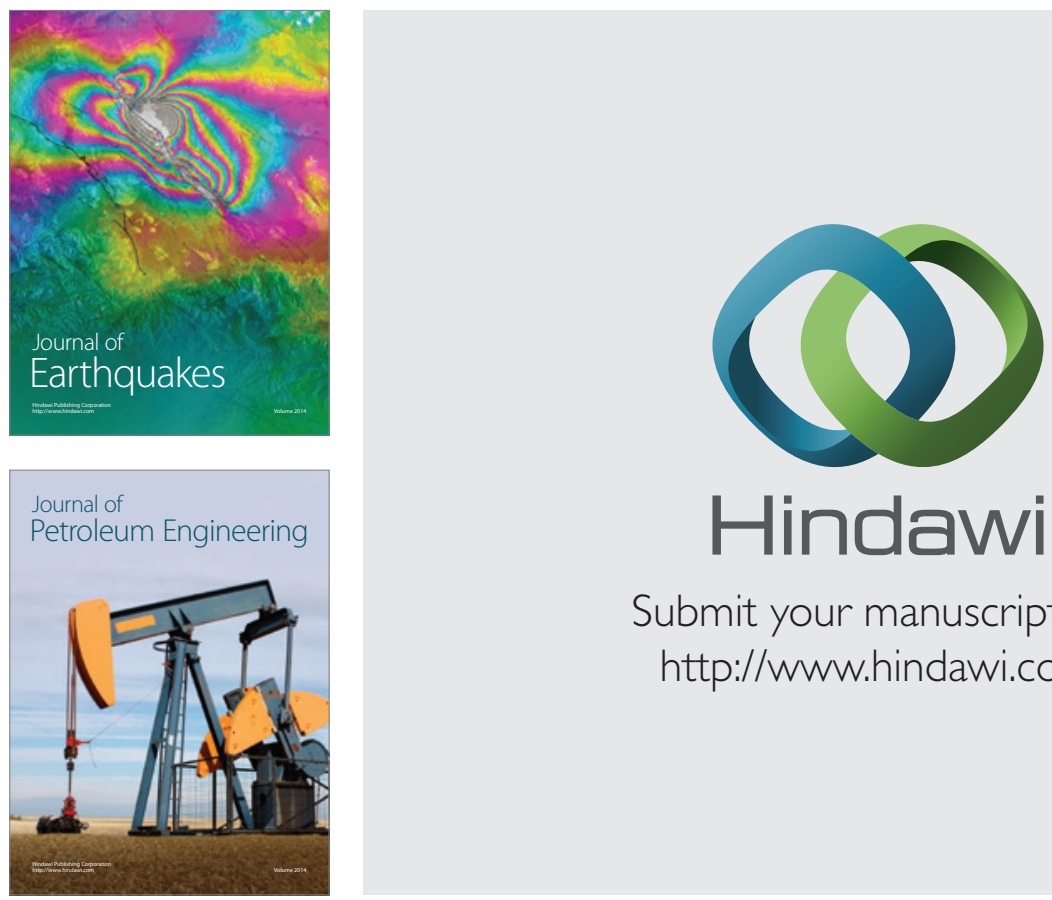

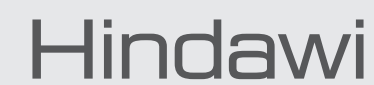

Submit your manuscripts at

http://www.hindawi.com
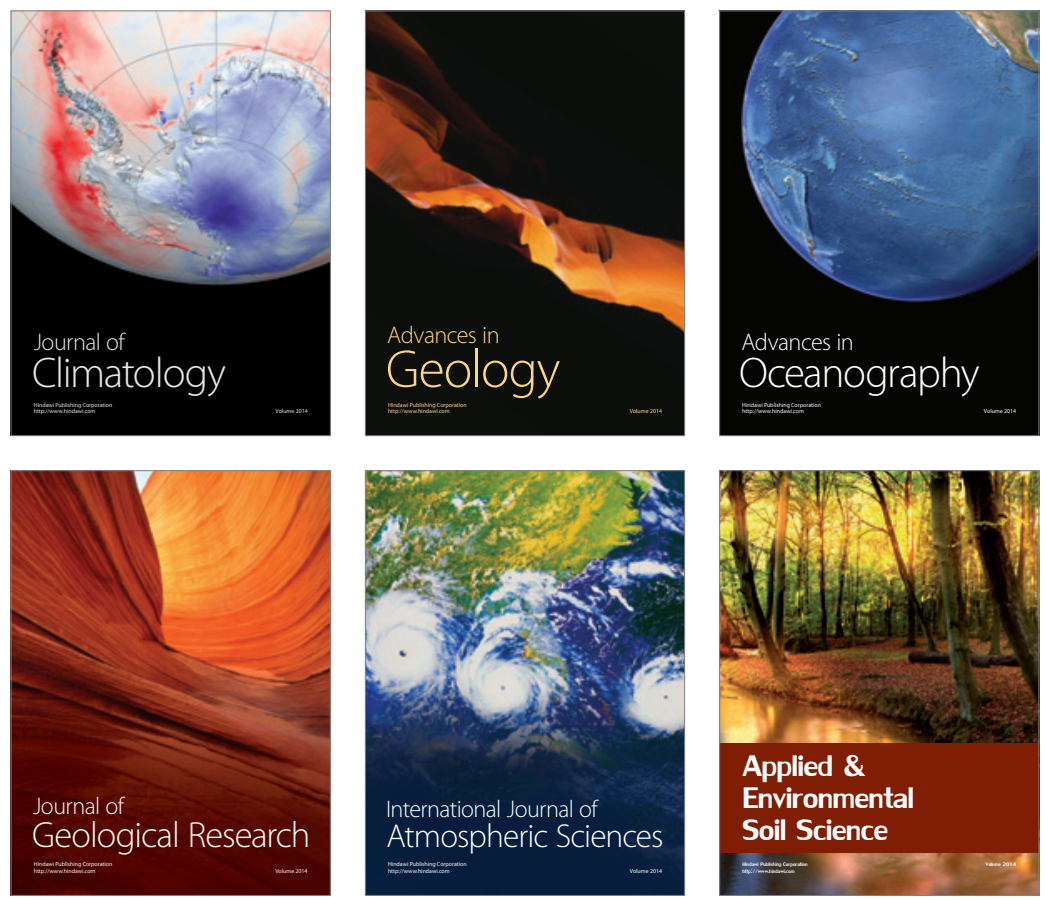
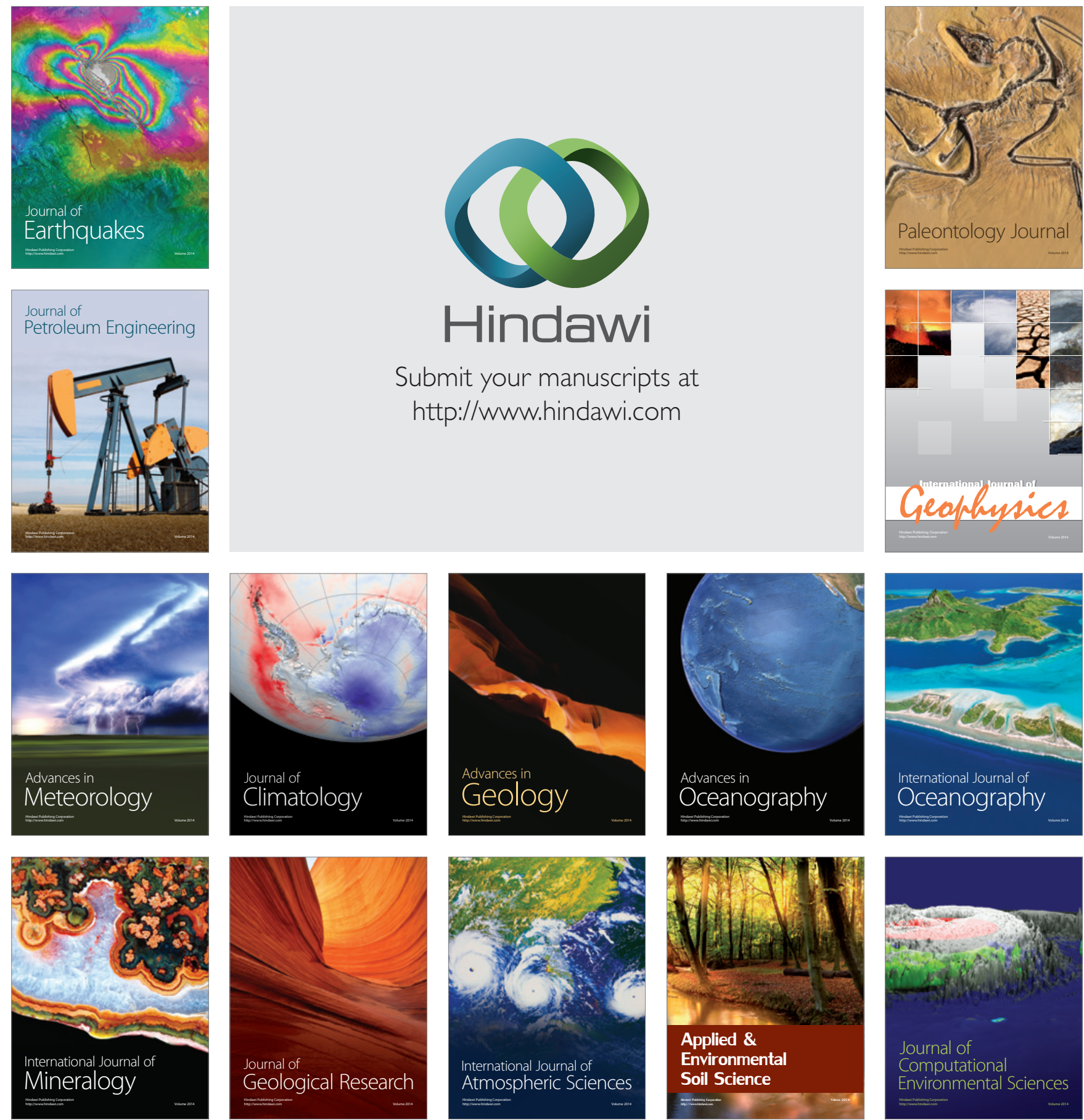